\section{A Dangerous Octopus Fishing: Kounis Syndrome Following an Octopus Bite}

Sir,

Kounis syndrome is defined as the concurrence of acute coronary syndromes in the setting of hypersensitivity reactions. In this context, the heart plays a pivotal role, acting as both the source and the target of inflammatory mediators, which actively contribute to atherosclerotic plaque destabilisation. ${ }^{1,2}$

A 67-year man complained about flushing, vomiting and diarrhea, with conjunctivitis and a diffuse urticarial rash almost 30 minutes after being bitten by an octopus (Eledone spp.) (Figure 1A), during underwater fishing. At hospital admission, he experienced acute-onset wheezing with oppressive, retrosternal chest pain. His blood pressure was $90 / 60 \mathrm{mmHg}$. Bronchospasm was noticed, and an erythematous cutaneous torn wound with edematous edges was detected on the right calf, at the site of the octopus bite (Figure 1B). A 12-lead electrocardiogram showed ST-elevation in the inferior leads, extended to the lateral precordial leads $V_{5}-V_{6}$, with reciprocal $\mathrm{ST}$-depression in leads I, aVL and $\mathrm{V}_{1}-\mathrm{V}_{3}$ (Figure $1 \mathrm{C}$ ). Transthoracic echocardiography revealed a mild reduced systolic function, with inferolateral wall hypokinesis. Intravenous hydrocortisone, intramuscular chlorphenamine and fluid resuscitation were administered, with a partial clinical benefit. Then, the patient underwent emergency coronary angiography, which showed a $95 \%$ stenosis in the proximal tract of the right coronary artery (Figure 1D), that was treated by positioning a drugeluting stent. After cardiologic discharge, further diagnostic investigations ruled out carcinoid syndrome and systemic mastocytosis.

Mast cells are the target effectors of hypersensitivity reactions, by triggering the release of systemic mediators. ${ }^{3}$ Cardiac mast cells are widely distributed in human heart, mainly around the adventitia of epicardial coronary arteries, as well as in close contact with small intramural coronary vessels. Uniquely, they can be directly activated both by allergenic and nonallergenic triggers, including anaphylatoxins, $\mathrm{C} 3 \mathrm{a}$ and $\mathrm{C} 5 \mathrm{a}$ and substance P. ${ }^{2,4}$ As previously reported by Kounis et al. ${ }^{1}$, several foods, drugs and environmental exposures are known as potential inducers of mastocyte activation.

Eledoisin was the first tachykinin sequenced from the posterior salivary gland of the Mediterranean octopus Eledone moschata, while other tachykinin-related peptides were isolated from the Octopus vulgaris and other nonmammalian species. ${ }^{5}$ They have been shown to exhibit a wide substance Plike physiologic spectrum, including local vasodilatation and altered vascular permeability; extravascular smooth muscle cells activation and triggering of inflammatory response. ${ }^{4,5}$

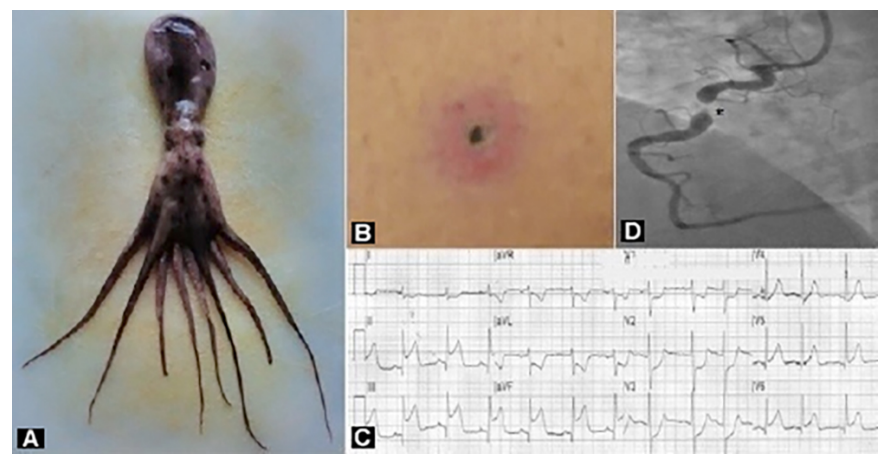

Figure 1: A: Octopus, Eledone spp. B: Erythematous cutaneous wound torn with edematous edges, at the site of the bite. C: Twelvelead electrocardiogram at hospital admission. D: Coronary angiography showing a subocclusive lesion in the proximal tract of right coronary artery (asterisk).

To the best of authors' knowledge, this is the first reported case of Kounis syndrome triggered by an octopus bite. Clinicians should be aware to actively look for cardiac involvement whenever a hypersensitivity reaction is suspected.

\section{CONFLICT OF INTEREST:}

Authors declared no conflict of interest.

\section{AUTHORS' CONTRIBUTION:}

RS: Conception and design, acquisition of data, drafting of manuscript and critical review.

GS: Conception and design, acquisition of data, critical review. CB: Acquisition of data, critical review, supervision.

\section{REFERENCES}

1. Kounis NG, Koniari I, Velissaris D, Tzanis G, Hahalis G. Kounis syndrome not a single-organ arterial disorder but a multisystem and multidisciplinary disease. Balkan Med J 2019; 36(4):212-21.

2. Triggiani M, Patella V, Staiano RI, Granata F, Marone G. Allergy and the cardiovascular system. Clin Exp Immunol 2008; 153(Supp1):7-11.

3. Theoharides TC, Kalogeromitros D. The critical role of mast cells in allergy and inflammation. Ann N Y Acad Sci 2006; 1088:78-99.

4. O'Connor TM, O'Connell J, O'Brien DI, Goode T, Bredin $C P$, Shanahan $F$. The role of substance $P$ in inflammatory disease. J Cell Physiol 2004; 201(2):167-80.

5. Almeida TA, Rojo J, Nieto PM, Pinto FM, Hernandez M, Martín JD, et al. Tachykinins and tachykinin receptors: Structure and activity relationships. Curr Med Chem 2004; 11(15):2045-81. 


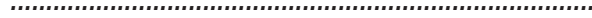

Department of Internal Medicine, Cardiovascular Disease Unit, IRCCS Ospedale Policlinico San Martino, University of Genova, Genova, Italy

Correspondence to: Riccardo Scagliola, Cardiovascular Disease Unit, IRCCS Ospedale Policlinico San Martino,
Largo R. Benzi n.10, 16132 Genova, Italy

E-mail: risca88@live.it

Received: December 22, 2018; Revised: September 12, 2019;

Accepted: September 17, 2019

DOI: https://doi.org/10.29271/jcpsp.2020.06.675 